\section{Neoplasia Endócrina Múltipla Tipo 1: Diagnóstico Clínico, Laboratorial e Molecular e Tratamento das Doenças Associadas}

\begin{abstract}
RESUMO
As síndromes de neoplasias endócrinas múltiplas (NEM) incluem as do tipo 1 (MEN 1) e 2 (MEN 2), a síndrome de von Hippel-Lindau, neurofibromatose tipo 1 e o complexo de Carney. Estas são síndromes genéticas complexas decorrentes de ativação ou inativação de diferentes tipos de genes envolvidos na regulação da proliferaçăo celular. Nesta revisão, discutiremos as manifestações clínicas e o acompanhamento da MEN 1, assim como o rastreamento genético de potenciais portadores de alterações no gene MEN 1. A MEN 1 inclui o desenvolvimento de hiperparatiroidismo primário multifocal, tumores de ilhotas pancreáticas e adenomas de hipófise. Além disso, alguns pacientes podem apresentar manifestações cutâneas como angiofibromas e colagenomas e ainda podem desenvolver outras neoplasias como tumores carcinóides, tumores de tiróide, adenomas de adrenal, lipomas, feocromocitomas e meningiomas. A MEN 1 é uma síndrome hereditária, transmitida de forma autossômica dominante e causada por mutação inativadora do gene MEN 1. O gene MEN 1 codifica uma proteína denominada "menin", que é um gene supressor tumoral. Vários estudos demonstraram sua importância na regulação da proliferação celular e confirmaram seu papel na patogênese da MEN 1. A identificação do gene MEN 1 e sua análise genética resultaram na possibilidade de monitoração de pacientes que ainda não apresentam manifestações clínicas associadas a esta síndrome e diagnóstico precoce e tratamento dos pacientes afetados. Tais medidas poderão implicar em sobrevida maior para estes pacientes. Estudos adicionais visando uma melhor compreensão da função e dos mecanismos de sinalização da proteína "menin" poderão propiciar alternativas terapêuticas para os pacientes que evoluem com malignização de tumores relacionados à MEN 1, podendo resultar em maior sobrevida. (Arq Bras Endocrinol Metab 2005;49/5:735-746)
\end{abstract}

Descritores: Neoplasia Endócrina Múltipla tipo 1; Hiperparatiroidismo primário; Tumor de ilhotas pancreáticas; Adenoma de hipófise; Rastreamento bioquímico e genético

\begin{abstract}
Multiple Endocrine Neoplasia Type 1 (MEN 1): Clinical, Biochemical and Molecular Diagnosis and Treatment of the Associated Disturbances.

Multiple endocrine neoplasia (MEN) syndromes include types 1 (MEN 1) and 2 (MEN 2), von Hippel-Lindau syndrome, neurofibromatosis type 1 and Carney complex. These are complex genetic syndromes caused by activation or inactivation of different types of genes known to be involved in the regulation of cell proliferation. In this review we will discuss the clinical manifestations and management of the MEN 1 syndrome as well as the genetic screening of potential MEN 1 gene carriers. MEN 1 is a hereditary syndrome, transmitted in an autosomic dominant fashion and caused by an inactivating mutation of the MEN 1 gene, characterized by the development of primary hyperparathyroidism, islet cell tumors and pituitary adenomas. In addition, these patients can pre-
\end{abstract}

\author{
Ana Oliveiva Hoff \\ Omar Magid Hauache
}

MD Anderson Cancer Center (AOH), Houston, Texas; Setor de Endocrinologia, Fleury - Centro de Medicina Diagnóstica (OMH); e Disciplina de Endocrinologia, Escola Paulista de Medicina/

Universidade Federal de São Paulo (AOH, OMH), São Paulo, SP.
Recebido em 16/08/04 Revisado em 24/05/05 Aceito em 20/08/05 
sent with cutaneous manifestations such as angiofibromas and collagenomas, and can develop other neoplastic manifestations including carcinoids, thyroid tumors, adrenal adenomas, lipomas, pheochromocytomas and meningiomas. The MEN 1 gene encodes a peptide which is a tumor suppressor gene called menin. Several studies have demonstrated its importance in regulation of cell proliferation and have confirmed its role in the pathogenesis of the MEN 1 syndrome. The discovery of the MEN 1 gene and the genetic analysis of MEN 1 patients have resulted in earlier diagnosis and treatment of asymptomatic carriers which can potentially result in a longer survival of these patients. Further investigation of the function and signaling pathways of the menin protein will hopefully offer therapeutic alternatives to patients with malignant progression of MEN 1-related tumors and also result in improved survival. (Arq Bras Endocrinol Metab 2005;49/5:735746)

Keywords: Multiple Endocrine Neoplasia type 1; Primary hyperparathyroidism; Islet cell tumor; Pituitary adenoma; Biochemical and genetic screening

A SEOPLASIAS ENDÓCRINAS MÚLTIPLAS são síndromes complexas, genéticas, transmitidas de forma autossômica dominante. Estas síndromes incluem as neoplasias endócrinas múltiplas tipo 1 e 2 , a síndrome de von Hippel-Lindau, a neurofibromatose tipo 1 e o complexo de Carney (tabela 1). Serão discutidas, nesta revisão, as manifestações clínicas e o tratamento da neoplasia endócrina múltipla tipo 1 (MEN 1), bem como comentaremos sobre aspectos moleculares relacionados ao diagnóstico de MEN 1 e como esta informação deve se adaptar à prática médica.

A associação de tumores das paratiróides, ilhotas pancreáticas e hipófise caracteriza a MEN 1, descrita inicialmente em 1954 por Wermer, e por esta razão também conhecida como síndrome de Wermer (1). Além das manifestações típicas descritas, os portadores de MEN 1 possuem predisposição ao desenvolvimento de outras neoplasias, como tumores adrenais, tumores carcinóides, angiofibromas faciais, colagenomas, lipomas, feocromocitomas e meningiomas (2-4).

Estima-se que a prevalência da MEN 1 varia de 0,01 a 2,5 por 1.000. As manifestações clínicas da doença estão relacionadas com o órgão afetado e podem incluir efeitos de massa devido ao tamanho do tumor, hipersecreção hormonal e malignidade (2). O termo "múltipla" aplica-se para descrever a multiplicidade de tumores que ocorrem em um mesmo órgão (como nas paratiróides ou nas ilhotas pancreáticas) e também para descrever a ocorrência de tumores em diferentes órgãos endócrinos. Alguns tumores que fazem parte da MEN 1, como os de paratiróides e gastrinomas, geralmente são diagnosticados uma ou mais décadas mais cedo que os tumores esporádicos presentes nos mesmos tipos de tecidos. A maioria dos tumores relacionados com MEN l é benigna, mas alguns tumores enteropancreáticos, como os gastrinomas e tumores carcinóides, podem ser malignos, sendo estas as maiores causas de morte em pacientes com MEN l (2). A MEN l é uma síndrome genética, com transmissão autossômica dominante de alta penetrância e causada por uma mutação que inativa o gene $M E N ~ 1$, que é um gene supressor tumoral. A MEN l é considerada familial quando um indivíduo apresenta MEN 1 e pelo menos um parente de primeiro grau apresenta no mínimo uma das características de MEN 1 , ou seja, a presença de tumor em pelo um dos três tecidos mais freqüentemente afetados $(5,6)$.

O tratamento de MEN l é complexo e a cura é difícil. Os pacientes freqüentemente necessitam de várias intervenções médicas e cirúrgicas ao longo de suas vidas, já que os tumores têm alto potencial recidivante e causam síndromes hormonais importantes (2). A decisão cirúrgica deve ser individualizada, levandose em conta as suas possíveis seqüelas, que incluem hipoparatiroidismo, hipopituitarismo e insuficiência pancreática exócrina e endócrina.

\section{Hiperparatiroidismo primário}

O hiperparatiroidismo primário, presente em 90-97\% dos portadores desta síndrome, é geralmente a primeira manifestação da MEN $1(5,7)$. A avaliação bioquímica prospectiva de famílias com MEN 1 demonstrou que o hiperparatiroidismo primário começa a se manifestar já na segunda década de vida. Portanto, espera-se que aos 40 anos de idade a maioria dos indivíduos já terá apresentado alguma forma de hiperparatiroidismo (8).

Ao contrário do hiperparatiroidismo primário esporádico, que tem como causa mais freqüente um único adenoma de paratiróide, na MEN 1 o hiperparatiroidismo é decorrente da hiperplasia de duas ou mais paratiróides. As manifestações clínicas, no entanto, são similares ao hiperparatiroidismo esporádico. $\mathrm{O}$ mais comum é a identificação de hipercalcemia assintomática; entretanto, quando esta não é identificada precocemente, as manifestações do hiperparatiroidismo tardio, como nefrolitíase, osteoporose, fraturas ósseas e sintomas decorrentes de hipercalcemia grave, podem ocorrer.

O diagnóstico diferencial da hipercalcemia familial inclui não só MEN 1, mas também MEN 2A, 
Tabela 1. Síndromes genéticas associadas a neoplasias endócrinas múltiplas (6,26).

\begin{tabular}{|c|c|c|}
\hline Síndrome & Principais Manifestaçōes clínicas & Anormalidade genética \\
\hline MEN 1 & $\begin{array}{l}\text { Adenomas hipofisários } \\
\text { Hiperparatiroidismo primário } \\
\text { Tumores das ilhotas pancreáticas } \\
\text { Tumores do córtex adrenal } \\
\text { Angiofibroma cutâneo } \\
\text { Lipomas }\end{array}$ & $\begin{array}{l}\text { Mutação inativadora do gene MEN } 1 \\
\text { (1 1q13) que codifica a proteína menin }\end{array}$ \\
\hline von Hippel-Lindau & $\begin{array}{l}\text { Feocromocitoma } \\
\text { Tumores das ilhotas pancreáticas } \\
\text { Hemangioblastoma do SNC } \\
\text { Angiomas da retina } \\
\text { Hipernefromas } \\
\text { Cistos viscerais } \\
\text { Neurofibromas }\end{array}$ & $\begin{array}{l}\text { Mutação inativadora do gene VHL } \\
\text { (3p25) que codifica a proteína elongin }\end{array}$ \\
\hline Neurofibromatose tipo 1 & $\begin{array}{l}\text { Tumores endócrinos associados: } \\
\text { feocromocitoma } \\
\text { carcinoma medular de tiróide } \\
\text { hiperparatiroidismo primário } \\
\text { tumor carcinóide produtor de } \\
\text { somatostatina }\end{array}$ & $\begin{array}{l}\text { Mutação inativadora do gene NF-1 } \\
\text { (17q11.2) que codifica a proteína neu- } \\
\text { rofibromin }\end{array}$ \\
\hline MEN 2 & $\begin{array}{l}\text { Carcinoma Medular de tiróide } \\
\text { Feocromocitoma } \\
\text { Hiperparatiroidismo primário }\end{array}$ & $\begin{array}{l}\text { Mutação ativadora do proto-onco- } \\
\text { gene RET que codifica o receptor RET }\end{array}$ \\
\hline Complexo de Carney & $\begin{array}{l}\text { Pigmentação cutânea puntiforme } \\
\text { Mixoma cardíaco } \\
\text { Mixoma cutâneo } \\
\text { Doença adrenocortical pigmentar } \\
\text { nodular primária } \\
\text { Tumor de células de Sertoli } \\
\text { Acromegalia } \\
\text { Schwannoma }\end{array}$ & $\begin{array}{l}\text { Mutação inativadora do gene } \\
\text { PRKAR1A (17q22-24) identificada em } \\
\text { algumas famílias }\end{array}$ \\
\hline
\end{tabular}

Abreviações: MEN 1, neoplasia endócrina múltipla tipo 1; SNC, sistema nervoso central; VHL, von Hippel-Lindau; NF1, neurofibromatose tipo 1; MEN 2, neoplasia endócrina múltipla tipo 2; PRKAR1A, protein kinase $A$ (PKA) type l-a reg ulatory subunit (Rla)

hipercalcemia hipocalciúrica familial, hiperparatiroidismo adenomatoso familial e hiperplasia paratiroidiana familial. Cada uma destas síndromes resulta em manifestações clínicas semelhantes, porém são decorrentes de alterações moleculares distintas (9). O tratamento do hiperparatiroidismo primário da MEN l é cirúrgico $(10,11)$. Porém, o momento da intervenção e o melhor procedimento cirúrgico ainda são controversos (12). Não há dúvida que pacientes que se apresentam com manifestações importantes do hiperparatiroidismo devem ser submetidos à paratiroidectomia. As indicações cirúrgicas incluem cálcio sérico maior que $12 \mathrm{mg} / \mathrm{dL}$, urolitíase e doença óssea decorrente do hiperparatiroidismo. Não é claro, entretanto, quando intervir naqueles pacientes com hiperparatiroidismo com níveis de cálcio inferiores a $12 \mathrm{mg} / \mathrm{dL}$. Nestes casos, é sabido que pacientes com síndrome de Zollinger-Ellisson concomitante se beneficiam da paratiroidectomia, pois esta diminui o estímulo à hipersecreção de gastrina. Em outros pacientes, o atraso na indicação da paratiroidectomia é seguro quando o acompanhamento periódico do nível de cálcio, creatinina, cálcio urinário e densitometria óssea é possível.

Como o envolvimento de todas as paratiróides é freqüente, o tratamento se faz via paratiroidectomia subtotal (3 glândulas e meia) ou paratiroidectomia total com o enxerto heterotópico de tecido paratiroidiano (13). Infelizmente não há um estudo prospectivo e randomizado comparando estes dois procedimentos cirúrgicos.

A fim de minimizar o risco de recidiva do hiperparatiroidismo, muitos investigadores favorecem a paratiroidectomia total com o enxerto feito no antebraço não dominante. Apesar de resultar em risco maior de hipoparatiroidismo (6\% em mãos experientes) (14), esta técnica oferece as seguintes vantagens: em primeiro lugar, facilita eventual intervenção cirúrgica subseqüente, pois, em caso de recidiva do hiper- 
paratiroidismo, o tratamento se faz com a ressecção de ilhotas de tecido paratireoidiano do antebraço não dominante. Em segundo lugar, pode simplificar a avaliação da função do enxerto, medindo-se o nível de paratormônio coletado acima da drenagem venosa do implante no antebraço que abriga o enxerto e comparando este valor com o nível medido no antebraço contralateral. Desta maneira, pode-se também identificar se o hiperparatireoidismo recorrente é devido à hiperplasia de tecido enxertado ou se é decorrente de hiperplasia de tecido residual deixado em região cervical (15). Como a paratiroidectomia total pode resultar em hipoparatiroidismo grave, especialmente quando praticada por cirurgiões com pouca experiência, há investigadores que recomendam a paratiroidectomia subtotal. Um estudo retrospectivo realizado no Nation al Institutes of Health nos Estados Unidos revelou que os índices de recorrência após paratiroidectomia subtotal e total foram de $33 \%$ e $23 \%$, respectivamente, e que, de fato, a paratiroidectomia subtotal resultou em menos casos de hipoparatiroidismo. Em centros onde a técnica de paratiroidectomia total não é a rotina, deve-se realizar a paratiroidectomia subtotal (16).

Enquanto a ressecção de um adenoma de paratiróide resulta em uma cura definitiva em mais de 85\% dos pacientes portadores de hiperparatiroidismo primário esporádico, em pacientes com MEN 1 a pers- pectiva de cura é menor e depende da extensão do procedimento cirúrgico. De acordo com vários estudos, quando a paratiroidectomia total ou subtotal é realizada, a normalização do cálcio sérico ocorre em 70\% a $100 \%$ dos casos. Entretanto, no período de uma década, 50\% destes pacientes recidivam (15,17-20). A recidiva em vários destes pacientes ocorre múltiplas vezes ao longo da vida, e portanto muitos requerem várias intervenções cirúrgicas. Este potencial de crescimento constante de células paratiroidianas reflete a anormalidade molecular intrínseca das células paratiroidianas destes indivíduos $(21,22)$.

\section{Tumores das ilhotas pancreáticas}

A segunda manifestação mais comum em pacientes com MEN l é o desenvolvimento de tumores multicêntricos e pluripotentes das ilhotas pancreáticas, visto em $75 \%$ a $81 \%$ dos pacientes $(8,23)$. O acometimento pancreático é tipicamente multifocal e as lesões são chamadas de pluripotentes pois podem secretar um ou mais tipos de hormônios diferentes. Os hormônios produzidos mais freqüentemente são os seguintes: gastrina, insulina, glucagon, somatostatina, VIP e ACTH (tabela 2). Ao contrário dos tumores paratiroidianos e hipofisários, os tumores pancreáticos têm potencial para malignização: $30 \%$ a $60 \%$ dos pacientes com lesões pancreáticas desenvolvem metástases hepáticas no

Tabela 2. Manifestações clínicas em MEN $1(6,26)$.

\begin{tabular}{lll}
\hline Síndrome & Manifestações Clínicas & Penetrância \\
\hline MEN 1 & Hiperparatiroidismo primário & $90 \%-97 \%$ \\
& Tumores das ilhotas pancreáticas: & $75 \%-81 \%$ \\
& Gastrinoma & \\
Insulinoma & \\
Ppoma ou "não-funcionante" & $10 \%-65 \%$ \\
Glucagonoma, VIPoma, somatostatinoma & \\
Adenomas hipofisários & \\
Prolactinoma & \\
Tumor secretor de GH & Não-funcionante & \\
Tumor secretor de ACTH & \\
Tumor secretor de TSH & $5 \%-10 \%$ \\
Carcinóides & \\
Estômago & \\
Timo & \\
Brônquio & $20 \%-41 \%$ \\
Adenoma do córtex adrenal & raro \\
Carcinoma do córtex adrenal & $30 \%$ \\
Lipomas & $5 \%$ \\
Tumores das células foliculares da tiróide & $85 \%$ \\
Angiofibroma facial & $70 \%$ \\
Colagenoma & $<1 \%$ \\
Ependimoma & $<1 \%$ \\
Feocromocitomas & $?$ \\
Meningiomas &
\end{tabular}

Abreviações: MEN 1, neoplasia endócrina múltipla tipo 1; VIPoma, tumor secretor de peptídeo intestinal vasoativo; GH, hormônio de crescimento; ACTH, hormônio adrenocorticotrófico; TSH, hormônio estimulante da tiróide 
decorrer da vida (24).

As manifestações clínicas dependem da quantidade e tipos de hormônios neuroendócrinos produzidos pelos tumores. O gastrinoma é o tumor de ilhotas mais freqüente em pacientes com MEN 1. De fato, $25 \%$ de todos os gastrinomas estão associados à MEN l (25). O gastrinoma causa a síndrome de ZollingerEllisson, caracterizada por úlceras pépticas comumente refratárias ao tratamento médico e diarréia crônica. Em pacientes com MEN 1, gastrinomas duodenais são mais comuns que os gastrinomas pancreáticos. Caracterizam-se por se apresentarem como tumores muito pequenos, submucosos e multicêntricos (26). O segundo tumor mais freqüente é o insulinoma, que causa sintomas decorrentes da hipoglicemia. Outras possíveis manifestações clínicas incluem o diabetes mellitus e dermatose (eritema necrolítico migratório) decorrente de um glucagonoma; diarréia, hipercalemia e acidose metabólica decorrente de um tumor secretor de VIP (síndrome de Werner-Morrison), e hipercalcemia decorrente de um tumor secretor de peptídeo relacionado ao PTH (PTH-rp) (tabela 2).

A avaliação bioquímica prospectiva de pacientes com MEN 1 demonstrou que os tumores de ilhotas tendem a secretar o polipeptídeo pancreático, insulina e pró-insulina em estágios precoces de desenvolvimento, antes mesmo de serem detectados por imagens radiológicas. Por isso, a localização destes tumores é difícil, complicando a sua remoção cirúrgica. Já a gastrina tende a ser secretada em um estágio mais tardio quando as lesões são detectáveis em imagens radiológicas (27). De certa forma, isto é uma desvantagem, pois se sabe que quanto maior o gastrinoma maior é a chance de malignização.

O tratamento dos tumores de ilhotas pancreáticas associados à MEN l é complexo e diferente dos tumores esporádicos. O tratamento deve ser individualizado de acordo com o tipo de tumor. Como na síndrome MEN 1 os tumores são múltiplos e pequenos, a chance de cura através da cirurgia é pequena. No caso do gastrinoma, ainda existe controvérsia quanto à melhor conduta terapêutica, que pode ser cirúrgica ou via tratamento medicamentoso. A disponibilidade de drogas eficazes para o tratamento dos sintomas de ZES e a falta de resultados positivos em vários estudos que avaliaram a intervenção cirúrgica (28) resultaram na indicação do tratamento médico como sendo a escolha inicial. Entretanto, há razões para se preocupar quando a conduta clínica é o único tratamento. Primeiro, os gastrinomas são lesões que têm potencial metastático (30\% dos casos), principalmente quando maiores de $3 \mathrm{~cm}$. Segundo, há casos relatados de carcinóides gástricos que se desenvolveram após tratamento prolongado com omeprazole (29). Apesar disso, não está claro se a intervenção cirúrgica realizada mais precocemente (tumores $<3 \mathrm{~cm}$ ) e acompanhada de duodenotomia $(\sim 80 \%$ dos gastrinomas associados à MEN 1 se localizam no duodeno) (30), resultará num melhor índice de cura do ZES, em um menor desenvolvimento de metástases hepáticas e em maior sobrevida $(31,32)$. Simeone e cols. (31) recomendam duodenotomia, esvaziamento completo de linfonodos peripancreáticos, pancreatectomia distal e exploração cuidadosa da cabeça e corpo do pâncreas com enucleação de qualquer tumor encontrado. Um estudo interessante recentemente publicado comparou a evolução de pacientes com ZES em que a duodenotomia foi realizada de rotina com pacientes em que a intervenção cirúrgica não envolveu duodenotomia. Gastrinomas duodenais foram localizados mais freqüentemente nos pacientes que se submeteram a duodenotomia $(62 \%$ vs. $18 \% ; \mathrm{P}<0,00001$ ), e a taxa de cura em longo prazo foi maior nos pacientes submetidos a duodenotomia. Além disso, o risco de desenvolver metástase hepática foi menor nestes pacientes (33).

Vale a pena ressaltar que a pancreatectomia total, apesar de resultar em cura, não é indicada pois resulta em diabetes mellitus e insuficiência pancreática exócrina. Este procedimento só é aceitável em pacientes de famílias que tenham uma incidência alta de doença metastática, pois neste caso, apesar das conseqüências, a pancreatectomia total pode evitar morte precoce $(12,34)$. Com a identificação do gene $M E N 1$ e das mutações causadoras desta síndrome, pensava-se que seria possível identificar as mutações associadas à malignização dos tumores pancreáticos e então poder identificar os pacientes com alto risco de desenvolver doença metastática. Entretanto, a análise mutacional de centenas de famílias ao redor do mundo não demonstrou qualquer correlação fenótipo-genótipo significativa (9). Pelas razões mencionadas acima, o objetivo cirúrgico é de retirar o máximo de massa tumoral sem que haja perda da função pancreática. No caso de outros tumores como o insulinoma, realiza-se a pancreatectomia distal com enucleação de tumores presentes na cabeça e corpo do pâncreas. Esta técnica comumente não resulta em diabetes mellitus, mas leva ao controle da hipersecreção hormonal.

Quando a intervenção cirúrgica não é indicada ou quando não resulta em controle da hipersecreção hormonal, os pacientes são tratados com terapia medicamentosa. Esta inclui os análogos da somatostatina (octreotide, lanreotide), que têm o poder de inibir a secreção de praticamente todos os hormônios, e de 
tratamentos mais específicos como os bloqueadores de bombas de próton para pacientes com gastrinomas (33) e a infusão contínua de glucagon, glicose ou diazóxido para pacientes com insulinoma (34). Os análogos da somatostatina são particularmente eficazes no controle da hipersecreção hormonal causada por VIPomas e glucagonomas e no controle da síndrome carcinóide.

A quimioterapia sistêmica é utilizada em pacientes com doença metastática progressiva. Os agentes quimioterápicos utilizados incluem a estreptozocina, doxorrubicina, 5-fluorouracil, dacarbazina e ciclofosfamida. A estreptozocina associada à doxorrubicina é atualmente o regime quimioterápico de escolha $(35,36)$. Quando comparada à estreptozocina somente, esta combinação melhora a resposta objetiva de $36 \%$ para $65 \%$, aumenta a duração média da resposta para 20 meses e aumenta a sobrevida $(37,38)$. As respostas completas são raras e a grande maioria dos pacientes recidiva. Por esta razão, e como geralmente trata-se de um processo indolente, a quimioterapia só deve ser iniciada quando o monitoramento periódico demonstra progressão significativa.

A embolização da artéria hepática, que resulta na isquemia e necrose do tecido tumoral, também faz parte da estratégia de tratamento de pacientes com metástases hepáticas (39). Este procedimento é útil para a redução das síndromes de hipersecreção hormonal, em particular nos casos de tumores produtores de insulina e VIP.

\section{Adenomas hipofisários}

A incidência de adenomas hipofisários em pacientes com MEN l varia de $10 \%$ a $65 \%(40,41)$. Em estudo multicêntrico recente, Vèrges e cols. (42) demonstraram que a prevalência de doença hipofisária em pacientes com MEN 1 pode chegar a $42 \%$ dos casos.

O envolvimento hipofisário é multicêntrico e pode causar diversos sintomas de acordo com o tipo de hormônio secretado. O prolactinoma é o tumor mais comum e causa galactorréia e amenorréia na mulher e hipogonadismo e disfunção erétil no homem. O tumor secretor de hormônio de crescimento $(\mathrm{GH})$ é o segundo mais comum, e causa manifestações clínicas de acromegalia. Os tumores menos freqüentes são os não-funcionantes e o secretor de hormônio adrenocorticotrófico (ACTH) que causa a doença de Cushing (43). Apesar de raro, há casos reportados de tumores produtores de tirotropina e de gonadotrofinas $(44,45)$. Apenas $25 \%$ dos adenomas hipofisários foram diagnosticados antes dos 26 anos de idade, e a doença hipofisária foi a manifestação inicial de MEN 1 em 17\% destes pacientes (42).

O tratamento varia de acordo com o tipo de tumor hipofisário. Prolactinomas são tratados com agonistas dopaminérgicos (ex. bromocriptina, cabergolina). A grande maioria dos pacientes (70-90\%) responde a este tratamento, demonstrando regressão do tamanho tumoral e normalização da prolactina e regressão dos sintomas. Pacientes que não toleram os agonistas dopaminérgicos ou que são resistentes a eles são candidatos à cirurgia transesfenoidal, combinada ou não, à radioterapia (46).

No caso de tumores produtores de GH, o tratamento primário é a cirurgia transesfenoidal, que resulta em um índice de cura entre 50\%-70\% dos casos. Entretanto, o índice de cura cai dramaticamente (10\%$30 \%$ ) quando os tumores são grandes e invasivos (47). Os análogos da somatostatina, o antagonista do receptor do $\mathrm{GH}$ ou a radioterapia são usados caso haja doença residual após a cirurgia ou em casos em que a cirurgia está contra-indicada (48-50).

\section{Outras manifestaçōes clínicas associadas à MEN 1}

Existem outras anormalidades associadas à MEN 1 (24). Estas incluem lipomas, angiofibromas, colagenomas, adenomas das glândulas tiróide, adenomas ou carcinomas das glândulas adrenais, carcinóides e meningiomas. Os carcinóides associados à MEN 1 envolvem o timo, pulmão, estômago ou duodeno. $\mathrm{O}$ carcinóide de timo ocorre em 0 a $8 \%$ de pacientes com MEN 1, é mais freqüente em homens e geralmente é assintomático, não causando Síndrome de Cushing ou Síndrome Carcinóide. O carcinóide de timo é potencialmente agressivo, sendo de mau prognóstico se detectado tardiamente. Por isso, principalmente em homens, a retirada do timo concomitante à paratiroidectomia tem sido recomendada. Além disso, a tomografia computadorizada do tórax deve ser realizada em todos os homens com MEN 1 no momento do diagnóstico e posteriormente, periodicamente durante o seguimento clinico (51). O carcinóide do estômago pode ocorrer em até $30 \%$ dos pacientes com MEN 1. Este tumor ocorre principalmente em pacientes com história de gastrinoma e associado ao tratamento crônico com inibidores de bomba de prótons (52). O carcinóide brônquico ocorre mais freqüentemente em mulheres (80\%) e 74\% deles são benignos. A síndrome carcinóide (diarréia, flushing e broncoespasmo) não é comum, mas já foram descritos carcinóides associados à $\mathrm{MEN} 1$ produtores de calcitonina e $\mathrm{ACTH}(53,54)$.

Tumores de glândulas adrenais ocorrem em 27\%-36\% dos pacientes com MEN 1. A anormalidade 
mais comum é o adenoma não-funcionante da adrenal. Entretanto, apesar de incomum, há casos de carcinoma adrenocortical em pacientes com MEN 1. Os tumores adrenais em MEN 1 devem ser tratados similarmente aos casos esporádicos (55).

\section{Genética molecular da MEN 1}

A análise sistemática de tumores derivados de pacientes com MEN 1 culminou na identificação do gene responsável pela MEN 1. Em 1988, Larsson e cols. mapearam a localização do gene responsável pela MEN 1 no braço longo do cromossomo 11 (1lql3) (56). Estes autores também demonstraram a perda de heterozigosidade $(\mathrm{LOH})$ deste locus, sugerindo então que MEN 1 era decorrente de um gene supressor de tumores e não de um oncogene, o que é consistente com a hipótese de desenvolvimento tumoral elaborada por Knudson (57). Este achado fez com que diferentes grupos na Europa e Estados Unidos analisassem intensivamente todos os genes contidos neste locus, culminando assim na identificação do gene que foi denominado MEN $1(58,59)$. Este gene contém 10 exons e codifica uma proteína que contem 610 aminoácidos, denominada "menin" (58).

Mais de 600 mutações germinativas já foram identificadas em famílias com MEN 1 (9,60). Estas mutações estão distribuídas por todos os 9 exons do gene MEN 1 (o exon 1 não é transcrito). Todas as mutações, que podem ser identificadas como sendo deleções, inserções, missense ou nonsense, são inativadoras e resultam em uma proteína truncada ou em última análise em uma proteína com comprometimento funcional (9). Como as mutações não envolvem áreas específicas (hot spots) do gene, a avaliação mutacional destes pacientes envolve todo o gene e é complexa. É estimado que 10\% das mutações germinativas MEN 1 são mutações de novo e podem ser passadas para gerações futuras. Além disso, 5 a $10 \%$ das mutações não são detectadas atualmente. Estes "falsos-negativos" podem ocorrer devido ao fato destas potenciais mutações estarem localizadas em regiões não codificadoras do gene ou por falta de sensibilidade do método de seqüenciamento disponível atualmente $(5,9)$.

Estudos de diversas famílias portadoras de MEN 1 e de tumores esporádicos permitem afirmar que não existe correlação genótipo-fenótipo em MEN $1(4,61)$. Famílias com manifestações clínicas muito semelhantes não possuem a mesma mutação e, da mesma forma, famílias com a mesma mutação não demonstram manifestações clínicas específicas àquela mutação. Um exemplo a ser descrito é o de três famílias que apresentam uma forma um pouco distinta de MEN 1, ou seja, pos- suem uma alta freqüência de prolactinomas $(62,63)$. A análise mutacional destas famílias revelou que, apesar de mostrarem um fenótipo específico, todas tinham mutações diferentes, sem correlação. Mais além, recentemente descrevemos um paciente que apresentava doença de Cushing como manifestação clínica inicial de MEN 1 e diagnóstico posterior de hiperparatiroidismo primário (43). Neste caso, a mutação identificada foi a R460X, mutação esta presente justamente em algumas destas famílias com incidência elevada de prolactinomas. Tal observação reforça a reconhecida expressividade variável dos tumores endócrinos freqüentemente observada em MEN 1 (64).

Mutações somáticas do gene MEN 1 também já foram descritas em tumores esporádicos incluindo adenomas da paratiróide (20\%), gastrinomas (33\%), tumores carcinóides do pulmão (36\%), lipomas (17\%) e insulinomas $(17 \%)$. Este fato reforça a importância de alterações do gene da MEN 1 na gênese destes tumores (65-68).

Ainda está sob investigação o mecanismo pelo qual a proteína "menin" leva à supressão de tumores. Sabe-se que "menin" é uma proteína nuclear que se liga ao fator de transcrição junD inibindo, assim, a ativação da transcrição genética mediada por junD (69). Além disso, estudos mais recentes demonstraram que "menin" também interage com outras proteínas como NFKB Pem, SMAD3, RPA2, FANCD2, NM23 beta, GFAP, vimentina e RUNX2, porém o papel fisiológico destas interações ainda não foi totalmente esclarecido e ainda não foi possível estabelecer a sinalização intracelular de "menin" em tecidos normais ou tumorais (70-78).

\section{Rastreamento bioquímico e genético de familiares de indivíduos com MEN 1}

$\mathrm{O}$ rastreamento em MEN 1, tanto genético quanto bioquímico, é importante pelo fato de que o reconhecimento precoce de uma alteração genética pode auxiliar na prevenção e/ou tratamento de algumas morbidades. Um programa de rastreamento de tumores pode ser suspenso em não-portadores e intensificado em pessoas que têm uma mutação identificada (4).

Antes da identificação do gene MEN 1, este rastreamento era feito exclusivamente através da análise bioquímica dos pacientes. Apesar deste rastreamento ser útil na identificação de indivíduos portadores da síndrome, ele não exclui precocemente os indivíduos não portadores, já que as manifestações clínicas podem ocorrer até a quinta década de vida. A exclusão precoce e precisa de portadores de MEN 1 só pode ser feita através da análise mutacional do gene $M E N 1$. 
Este é um dos grandes benefícios do rastreamento genético, pois $50 \%$ dos membros de uma família com MEN l podem, após a análise mutacional, ser poupados da ansiedade e da avaliação bioquímica feita durante o decorrer de suas vidas.

Outro benefício significante é o valor informativo do teste mutacional. Esta informação é importante para a confirmação do diagnóstico de MEN 1 em pacientes que apresentam um fenótipo consistente, mas que não possuem antecedentes familiares de MEN 1. Além disso, a informação do local e tipo de mutação facilita significativamente a análise mutacional dos outros membros da família.

Uma pergunta essencial é a idade ideal para se fazer o exame mutacional nos familiares de indivíduos com MEN 1. Não há um consenso sobre a idade em que se deve fazer a pesquisa genética. A maioria dos portadores de MEN 1 não desenvolve tumores malignos antes dos 18 anos de idade e, com essa idade, a própria pessoa poderia participar da decisão quanto à análise genética. Entretanto, os especialistas em MEN 1 não definiram a idade ideal a se fazer a avaliação; uma razão é o fato de existir um caso reportado de um macrodenoma hipofisário agressivo detectado aos 5 anos de idade (79). Atualmente, o recomendado é que a família receba um aconselhamento genético adequado para decidir quando prosseguir com a análise genética de seus filhos (80). Até muito recentemente, a avaliação mutacional do gene MEN 1 só podia ser realizada em poucos centros de pesquisa ao redor do mundo. Atualmente, a análise da seqüência do gene $M E N I$ é realizada em diversos centros no exterior como teste de rotina. Entretanto, a demanda limitada e a complexidade da análise, associada ao alto custo, são fatores limitantes para que tal análise seja difundida. A lista de laboratórios que realizam estes testes pode ser encontrada no site http://www.genetests.org.

Ao contrário dos indivíduos não portadores de uma mutação genética, os indivíduos portadores de uma mutação no gene MEN 1 devem continuar com o rastreamento clínico por toda a vida, a fim de que o desenvolvimento de um dos tumores seja detectado e tratado de acordo. Neste contexto, os exames recomendados atualmente em portadores de mutações germinativas do gene da MEN 1 estão incluídos na tabela $3(5,80)$. Estes indivíduos necessitam de uma avaliação completa (clínica, bioquímica e radiológica) que possa detectar qualquer manifestação clínica associada à síndrome MEN 1 . A avaliação deve incluir não só as dosagens de cálcio sérico, hormônio paratiroidiano e prolactina, mas também de IGF-1, cortisol sérico após teste de supressão com dexametasona; gastrina; glicose e insulina. Quando possível, deve-se dosar o polipeptídeo pancreático e a cromogranina sérica. Exames de imagem da hipófise e do pâncreas podem ser realizados a cada três anos ou mesmo a cada cinco anos. Estes exames não são realizados anualmente pois sabe-se que, principalmente no caso dos tumores pancreáticos, seu diagnóstico é baseado quase que exclusivamente no rastreamento bioquímico, pois a anormalidade dos hormônios pancreáticos precede a detecção radiológica destes tumores por pelo menos 5 anos $(81)$.

Entretanto, diferentemente do que ocorre na pesquisa de mutações do proto-oncogene RET para casos suspeitos de carcinoma medular de tiróide familiar ou fazendo parte da MEN 2A (onde a presença de mutação leva a uma recomendação de tiroidectomia precoce para prevenir ou curar o câncer), o conhecimento de estado de portador de mutação do gene da MEN 1 atualmente ainda não é suficiente para prevenir ou mesmo curar uma potencial malignidade.

É importante salientar que o gene da MEN l é

Tabela 3. Rastreamento prospectivo recomendável para portador de mutação do gene da neoplasia endócrina múltipla tipo $1(5,80)$.

\begin{tabular}{|c|c|c|c|}
\hline Tumor & $\begin{array}{l}\text { Idade para iniciar o } \\
\text { rastreamento (anos) }\end{array}$ & $\begin{array}{c}\text { Testes bioquímicos } \\
\text { anuais }\end{array}$ & $\begin{array}{c}\text { Exames de imagem a } \\
\text { cada } 3 \text { anos }\end{array}$ \\
\hline Adenoma de paratiróide & 8 & Cálcio, PTH & Nenhum \\
\hline Gastrinoma & 20 & Gastrina & Nenhum \\
\hline Insulinoma & 5 & Glicose, insulina & Nenhum \\
\hline \multicolumn{4}{|l|}{ Outros tumores } \\
\hline enteropancreáticos & 20 & Cromogranina- $A^{*}$ & $\begin{array}{c}\text { Cintilografia de receptor } \\
\text { de somatostatina*, TC ou } \\
\text { RM }\end{array}$ \\
\hline Tumores da hipófise anterior & 5 & $\begin{array}{l}\text { Prolactina } \\
\text { IGF-1 }\end{array}$ & \\
\hline & & Cortisol pós dexametasona & RM \\
\hline Carcinóide de timo ou brônquico & 20 & Nenhum & $\mathrm{TC}$ \\
\hline
\end{tabular}

Abreviações: TC, tomografia computadorizada; RM, ressonância magnética; PTH, paratormônio

* testes sem avaliação extensa para o rastreamento de MEN 1. 
grande e que as mutações estão difusamente espalhadas ao longo do gene. Diferentemente do proto-oncogene RET, não existem hot-spots. Conforme mencionamos anteriormente, uma limitação adicional é que cerca de $30 \%$ dos pacientes com MEN I não apresentam mutação na região codante ou nas splice junctions do gene da MEN 1, regiões estas rastreadas pelos métodos atuais. Assim, a decisão de se levar adiante um teste genético para MEN 1 pode ser difícil. Apesar de ser reconhecido que o achado de uma mutação no gene da MEN I não implica em intervenções terapêuticas de impacto, deve ser levado em conta o reconhecimento crescente de uma morbidade significativa associada à MEN 1 em idades cada vez mais precoces (79). O conhecimento do status de portador de mutação do gene da MEN 1 pode fornecer uma informação de grande utilidade para o paciente e para seu médico, auxiliando no diagnóstico precoce do tumor e conseqüentemente levando a uma diminuição de determinados tipos de morbidade associados a alguns tumores.

Candidatos para o teste de mutação do gene da MEN 1 incluem casos-índices que apresentam a doença e seus parentes. $\mathrm{O}$ teste genético também pode ser interessante naqueles pacientes que apresentam características sugestivas de $\operatorname{MEN~} 1$, mas que não preenchem critérios diagnósticos para MEN l (por exemplo, tumores paratiroideanos múltiplos antes dos 30 anos de idade ou tumores de ilhota múltiplos em qualquer idade). Nos casos em que nenhuma mutação é detectada num possível portador, é aconselhável um rastreamento periódico do tumor. Em algumas destas famílias, estudo genético de linkage é uma opção para o diagnóstico (4).

\section{Conclusão}

As síndromes de neoplasias endócrinas múltiplas são síndromes que fascinam pela riqueza de suas manifestações clínicas e pela possibilidade de atrelar a biologia molecular com a prática médica. A descoberta dos genes responsáveis por estas síndromes revolucionou não só a conduta médica destes pacientes e seus familiares, mas também tem proporcionado conhecimentos básicos importantes para se entender a função fisiológica destes genes. Pesquisas futuras relacionadas ao gene da MEN 1 terão como objetivo entender o mecanismo pelo qual este gene regula a proliferação celular e especificamente compreender o significado da interação deste com diversos fatores de transcrição genética. Além disso, a compreensão de seu papel no desenvolvimento embrionário normal também é de grande relevância, conforme pode ser observado em artigos recentes baseados em knockouts do gene da
MEN l (82-84).

Finalmente, estas descobertas podem também levar ao desenvolvimento de terapias genéticas via correção da mutação genética, que podem ser úteis para o controle do processo tumoral.

\section{REFERÊNCIAS}

1. Wermer P. Genetic aspects of adenomatosis of endocrine glands. Am J Med 1954;16:363-71.

2. Marx SJ, Agarwal SK, Kester MB, Heppner C, Kim YS, Skarulis MC, et al. Multiple endocrine neoplasia type 1: clinical and genetic features of the hereditary endocrine neoplasias. Recent Prog Horm Res 1999;54:397-438.

3. Dong Q, Debelenko LV, Chandrasekharappa SC, Lottreman C, Skarulis M, Emmert-Buck MR, et al. Loss of heterozygosity at 11q13: Analysis of pituitary tumours, lung carcinoids, lipomas, and other uncommon tumours in subjects with familial multiple endocrine neoplasia type 1. J Clin Endocrinol Metab 1997;82:1416-20.

4. Asgharian B, Chen Y-J, Patronas NJ, Pegjini PL, Reynolds JC, Vortmeyer A, et al. Meningiomas may be a component tumor of multiple endocrine neoplasia type 1. Clin Cancer Res 2004; 10:869-80.

5. Schussheim DH, Skarulis MC, Agarwal SK, Simonds WF, Burns AL, Spiegel AM, et al. Multiple endocrine neoplasia type 1: new clinical and basic findings. Trends Endocrinol Metab 2001;12:173-8.

6. Hoff AO, Cote GJ, Gagel RF. Multiple endocrine neoplasias. Ann Rev Phsiol 2000;62:377-411.

7. Calender A, Giraud S, Cougard P, Chanson P, Lenoir G, Murat $A$, et al. Multiple endocrine neoplasia type 1 in France: clinical and genetic studies. J Intern Med 1995;238:263-8.

8. Skogseid B, Eriksson B, Lundqvist G, Lorelius LE, Rastad J, Wide $L$, et al. Multiple endocrine neoplasia type 1: A 10year prospective screening study in four kindreds. J Clin Endocrinol Metab 1991;73:281-7.

9. Thakker RV. Genetics of endocrine and metabolic disorders: Parathyroid. Rev Endocr Metab Disord 2004;5:37-51.

10. Thompson NW. The surgical management of hyperparathyroidism and endocrine disease of the pancreas in the multiple endocrine neoplasia type 1 patient. J Intern Med 1995;238:269-80.

11. O'Riordain DS, O'Brien T, Grant CS, Weaver A, Gharib H, van Heerden JA. Surgical management of primary hyperparathyroidism in multiple endocrine neoplasia types 1 and 2 . Surgery 1993;114:1031-7.

12. Gagel RF. Multiple Endocrine Neoplasia. In: Wilson JD, Foster DW, Larsen PR, Kronenberg H, eds. Williams Textbook of Endocrinology. $9^{\text {th }}$ edition. Philadelphia:W.B. Saunders, 1998.p.1627-49.

13. Veldhuis JD, Norton JA, Wells Jr. SA, Vinik AI, Perry RR. Surgical versus medical management of multiple endocrine neoplasia (MEN) type 1. J Clin Endocrinol 


\section{Metab 1997;82:357-64}

14. Wells Jr. SA, Farndon JR, Dale JK, Leight GS, Dilley WG. Long-term evaluation of patients with primary parathyroid hyperplasia managed by total parathyroidectomy and heterotopic autotransplantation. Ann Surg 1980; $192: 451-8$.

15. Carling T, Udelsman R. Parathyroid Surgery in familial hyperparathyroid disorders. J Intern Med 2005;257:2737.

16. Elaraj DM, Skarulis MC, Libutti SK, Norton JA, Bartlett DL, Pingpank JF, et al. Results of initial operation for hyperparathyroidism in patients with multiple endocrine neoplasia type 1. Surgery 2003;134:858-64.

17. O'Riordain DS, O'Brien T, Grant CS, Weaver A, Gharib H, van Heerden JA. Surgical management of primary hyperparathyroidism in multiple endocrine neoplasia types 1 and 2 . Surgery 1993;114:1031-7.

18. Thompson NW. The surgical management of hyperparathyroidism and endocrine disease of the pancreas in the multiple endocrine neoplasia type 1 patient. J Intern Med 1995;238:269-80.

19. Burgess JR, David R, Parameswaran V, Greenaway TM, Sheperd JJ. The outcome of subtotal parathyroidecto$\mathrm{my}$ for the treatment of hyperparathyroidism in multiple endocrine neoplasia type 1. Arch Surg 1998;133:126-9.

20. Goudet P, Cougard P, Verges B Murat A, Carnaille B, Calender $A$, et al. Hyperparathyroidism in multiple endocrine neoplasia type 1: surgical trends and results of a 256-patient series from Groupe D'Etude des Neoplasies Endocriniennes Multiples Study Group. World J Surg 2001;25:886-90.

21. Rizzoli R, Green III J, Marx SJ. Primary hyperparathyroidism in familial multiple endocrine neoplasia type 1. Long-term follow-up of serum calcium levels after parathyroidectomy. Am J Med 1985;78:467-74.

22. van Heerden JA, Kent RBD, Sizemore GW, Grant CS, ReMine WH. Primary hyperparathyroidism in patients with multiple endocrine neoplasia syndromes. Surgical experience. Arch Surg 1983; 1 18:533-6.

23. Teh BT, Grimmond S, Shepherd J, Larsson C, Hayward N. Multiple endocrine neoplasia type 1: clinical syndrome to molecular genetics. Aust N Z J Surg 1995;65:708-13.

24. Melvin WS, Johnson JA, Sparks J, Innes JT, Ellison EC. Long-term prognosis of Zollinger-Ellison syndrome in multiple endocrine neoplasia. Surgery 1993;114:1183-8.

25. Jensen RT. Gastrin-producing tumors. Cancer Treat Res 1997; 89:293-334.

26. Hoff AO, Cote GJ, Gagel RF. Neuroendocrine cancers of the gastrointestinal tract: Islet cell carcinoma of the pancreas and other Neuroendocrine carcinomas. In: Abbruzzese JL, Evans DB, Willett CG, Fenoglio-Preiser C, eds. Gastrointestinal Oncology. Oxford:Oxford University Press, 2004.p.780-800.

27. Skogseid B, Oberg K. Prospective screening in multiple endocrine neoplasia type 1. H Ford Hosp Med J 1992; $40: 167-70$

28. MacFarlane MP, Fraker DL, Alexander HR, Norton JA, Lubensky I, Jensen RT. Prospective study of surgical resection of duodenal and pancreatic gastrinomas in multiple endocrine neoplasia type 1. Surgery 1995; 118:973-9.

29. Norton JA. Gastrinoma: advances in localization and treatment. Surg Oncol Clin N Am 1998;7:845-61.

30. Pipeleers-Marichal $M$, Somers $G$, Willems $G$, Foulis $A$, Imrie $C$, Bishop $A E$, et al. Gastrinomas in the duodenums of patients with multiple endocrine neoplasia type 1 and the Zollinger-Ellison syndrome. N Engl J Med 1990; 322:723-7.

31. Simeone DM, Scheiman JM, Thompson NW. The "serendipitous" surgical cure of the Zollinger-Ellison syndrome in a patient with multiple endocrine neoplasia type 1 despite an unsuspected diagnosis of either disease. J Clin Gastroenterol 2001;32:268-71.

32. Gauger PG, Thompson NW. Early surgical intervention and strategy in patients with multiple endocrine neoplasia type 1. Best Pract Res Clin Endocrinol Metab 2001; 15:213-23.

33. Norton J, Alexander HR, Fraker DL, Venzon DJ, Gibril F, Jensen RT. Does the use of routine duodenotomy (DUODX) affect rate of cure, development of liver metastases, or survival in patients with Zollinger-Ellison syndrome? Ann Surg 2004;239:617-26.

34. Hoff AO, Gagel RF. Multiple endocrine neoplasia types 1 and 2: Phenotype, genotype, diagnosis, and therapeutic plan with special reference to children and adolescents. Curr Op Endocrinol Diab 1997;4:91-9.

35. Hoff AO, Vassilopoulou-Sellin R. The role of glucagon administration in the diagnosis and treatment of patients with fumor hypoglycemia. Cancer 1998;82: 1585-92.

36. Miller CA, Ellison C. Therapeutic alternatives in metastatic neuroendocrine tumors. Surg Oncol Clin N Am 1998;7:863-79.

37. Moertel CG, Lefkopoulo M, Lipsitz S, Hahn RG, Klaassen D. Streptozocin-doxorubicin, streptozocin-fluorouracil, or chlorozotocin in the treatment of advanced islet cell carcinoma. N Engl J Med 1992;326:519-23.

38. Moertel CG, Hanley JA, Johnson LA. Streptozocin alone compared with streptozocin plus fluorouracil in the treatment of advanced islet-cell carcinoma. N Engl J Med 1980;303:1 189-94.

39. Ajani JA, Carrasco $\mathrm{CH}$, Charnsangavej C, Samaan NA, Levin B, Wallace $S$. Islet cell tumors metastatic to the liver: effective palliation by sequential hepatic artery embolization. Ann Intern Med 1988:108:340-4.

40. Scheithauer BW, Laws ERJ, Kovacs K, Horvath E, Randall RV, Carney JA. Pituitary adenomas of the multiple endocrine neoplasia type 1 syndrome. Semin Diagn Pathol 1987:4:205-11.

41. Burgess JR, Shepherd JJ, Parameswaran V, Hoffman L, Greenaway TM. Prolactinomas in a large kindred with multiple endocrine neoplasia type 1: Clinical features and inheritance pattern. J Clin Endocrinol Metab 1996;81:1841-5.

42. Vergès $B$, Boureille $F$, Goudet $P$, Murat $A$, Beckers $A$, Sassolas $G$, et al. Pituitary disease in MEN 1 type 1 (MEN 1): data from the France-Belgium MEN 1 Multicenter Study. J Clin Endocrinol Metab 2002;87:457-65.

43. Matsuzaki LN, Canto-Costa M, Hauache OM. Cushing's 
disease as first clinical manifestation of Multiple Endocrine Neoplasia type 1 (MEN 1) associated with R460X mutation of MEN 1 gene. Clin Endocrinol 2004; 60:142-3.

44. Taylor TJ, Donlon SS, Bale AE, Smallridge RC, Francis TB, Christensen RS, et al. Treatment of a thyrotropinoma with octreotide-LAR in a patient with multiple endocrine neoplasia-1. Thyroid 2000;10:1001-7.

45. Benito M, Asa SL, LiVolsi VA, West VA, Snyder PJ. Gonadotroph tumor associated with multiple endocrine neoplasia type 1. J Clin Endocrinol Metab 2005;90:570-4.

46. Losa M, Mortini P, Barzaghi R, Gioia L, Giovanelli M. Surgical treatment of prolactin-secreting pituitary adenomas: Early results and long-term outcome. J Clin Endocrinol Metab 2002;87:3180-6.

47. Beckers A, Betea D, Valdes Socin H, Stevenaert A. The treatment of sporadic versus $\mathrm{MEN}-1$ related pituitary adenomas J Int Med 2003;253:599-605.

48. Caron P, Beckers A, Cullen DR, Goth MI, Gutt B, Laurberg $P$, et al. Efficacy of the new long-acting formulation of lanreotide (lanreotide autogel) in the management of acromegaly. J Clin Endocrinol Metab 2002;87:4054-8.

49. Van der Lely AJ, Hutson RK, Trainer PJ, Besser GM, Barkan AL, Katznelson $L$, et al. Long-term treatment of acromegaly with pegvisomant, a growth hormone receptor antagonist. Lancet $2001 ; 358: 1754-9$.

50. Morange-Ramos I, Regis J, Dufour H, Andrieu JM, Grisoli F, Jaquet P, et al. Acta Gamma-knife surgery for secreting pituitary adenomas. Neurochir (Wien) 1998; 140:437-43.

51. Gibril F, Chen YJ, Schrump DS, Vortmeyer A, Zhuang Z, Lubensky IA, et al. Prospective study of thymic carcinoids in patients with multiple endocrine neoplasia typel. J Clin Endocrinol Metab 2003;88:1066-81.

52. Bordi C, Corletto VD, Azzoni C, Pizzi S, Ferraro G, Gibril F, et al. The antral mucosa as a new site for endocrine tumors in multiple endocrine neoplasia type 1 and Zollinger-Ellison syndromes. J Clin Endocrinol Metab $2001 ; 86: 2236-42$.

53. Amano S, Hazama F, Haebara $\mathrm{H}$, Tsurusawa $\mathrm{M}$, Kaito $\mathrm{H}$. Ectopic ACTH-MSH producing carcinoid tumor with multiple endocrine hyperplasia in a child. Acta Pathol Jpn 1978;28:721-30.

54. Samaan NA, Hickey RC, Bedner TD, Ibanez ML. Hyperparathyroidism and carcinoid tumor. Ann Intern Med 1975;82:205-7.

55. Skogseid B, Rastad J, Gobl A, Larsson C, Backlin K, Juhlin $C$, et al. Adrenal lesion in multiple endocrine neoplasia type 1. Surgery 1995;118:1077-82.

56. Larsson C, Skogseid B, Oberg K, Nakamura Y, Nordenskjold M. Multiple endocrine neoplasia type 1 gene maps to chromosome 11 and is lost in insulinoma. Nature 1988;332:85-7.

57. Knudson AG. Mutation and cancer: Statistical study of retinoblastoma. Proc Natl Acad Sci USA 1971;68:820-3.

58. Chandrasekharappa SC, Guru SC, Manickam P, Olufemi SE, Collins FS, Emmert-Buck MR, et al. Positional cloning of the gene for multiple endocrine neoplasiatype 1. Science 1997;276:404-7.
59. Lemmens I, Van de Ven WJ, Kas K, Zhang CX, Giraud S, Wautot $V$, et al. Identification of the multiple endocrine neoplasia type 1 (MEN 1) gene. The European Consortium on MEN 1. Hum Mol Genet 1997;6:1177-83.

60. Krawczak M, Ball EV, Fenton I, Stenson PD, Abeysinghe $\mathrm{S}$, Thomas $\mathrm{N}$, et al. Human gene mutation database-a biomedical information and research resource. Hum Mutat 2000;15:45-51.

61. Wautot V, Vercherat C, Lespinasse L, Chambe,B, Lenoir GM, Zhang CX, et al. Germline mutation profile of MEN 1 in Multiple Endocrine Neoplasia Type 1: search for correlation between phenotype and the functional domains of the MEN 1 protein. Hum Mutat 2002;20:3547.

62. Agarwal SK, Kester MB, Debelenko LV, Heppner C, Emmert-Buck MR, Skarulis MC, et al. Germline mutations of the MEN 1 gene in familial multiple endocrine neoplasia type 1 and related states. Hum Mol Genet 1997;6:1169-75.

63. Olufemi SE, Green JS, Manickam P, Guru SC, Agarwal $\mathrm{SK}$, Kester MB, et al. Common ancestral mutation in the MEN 1 gene is likely responsible for the prolactinoma variant of MEN 1 (MEN 1 Burin) in four kindreds from Newfoundland. Hum Mutat 1998; 11:264-9.

64. Carty SE, Helm AK, Amico JA, Clarke MR, Foley TP, Watson CG, et al. The variable penetrance and spectrum of manifestations of multiple endocrine neoplasia type 1. Surgery 1998; $124: 1106-14$

65. Heppner C, Kester MB, Agarwal SK, Debelenko LV, Emmert-Buck MR, Guru SC, et al. Somatic mutation of the MEN 1 gene in parathyroid tumours. Nat Genet 1997; 16:375-8.

66. Debelenko LV, Brambilla E, Agarwal SK, Swalwell JI, Kester MB, Lubensky IA, et al. Identification of MEN 1 gene mutations in sporadic carcinoid tumors of the lung. Hum Mol Genet 1997;6:2285-90.

67. Zhuang Z, Vortmeyer AO, Pack S, Huang S, Pham TA, Wang $C$, et al. Somatic mutations of the MEN 1 tumor suppressor gene in sporadic gastrinomas and insulinomas. Cancer Res 1997;57:4682-6.

68. Marx SJ, Agarwal SK, Kester MB, Heppner C, Kim YS, Emmert-Buck MR, et al. Germline and somatic mutation of the gene for multiple endocrine neoplasia type 1 (MEN 1). J Intern Med 1998;243:447-53.

69. Agarwal SK, Guru SC, Heppner C, Erdos MR, Collins RM, Park SY, et al. Menin interacts with the APl transcription factor JunD and represses JunD-activated transcription. Cell 1999;96:143-52.

70. Heppner C, Bilimoria KY, Agarwal SK, Kester M, Whitty LJ, Guru SC, et al. The tumor suppressor protein menin interacts with NF-kappaB proteins and inhibits NF-kappaBmediated transactivation. Oncogene 2001;20:4917-25.

71. Lemmens IH, Forsberg L, Pannett AA, Meyen E, Piehl F, Turner JJ, et al. Menin interacts directly with the homeobox-containing protein Pem. Biochem Biophys Res Commun 2001;286:426-31.

72. Agarwal SK, Lee Burns A, Sukhodolets KE, Kennedy PA, Obungu VH, Hickman AB, et al. Molecular pathology of the MEN 1 gene. Ann NY Acad Sci 2004;1014:189-98. 
73. Kaji H, Canaff L, Lebrun JJ, Goltzman D, Hendy GN. Inactivation of menin, a Smad3-interacting protein, blocks transforming growth factor type beta signaling. Proc Natl Acad Sci USA 2001;98:3837-42.

74. Sowa H, Kaji H, Hendy GN, Canaff L, Komori T, Sugimoto $\mathrm{T}$, et al. Menin is required for bone morphogenetic protein 2- and transforming growth factor beta-regulated osteoblastic differentiation through interaction with Smads and Runx2. J Biol Chem 2004;279:40267-75.

75. Jin S, Mao H, Schnepp RW, Sykes SM, Silva AC, D'Andrea $A D$, et al. Menin associates with FANCD2, a protein involved in repair of DNA damage. Cancer Res 2003;63:4204-10.

76. Yaguchi H, Ohkura N, Tsukada T, Yamaguchi K. Menin, the multiple endocrine neoplasia type 1 gene product, exhibits GTP-hydrolyzing activity in the presence of the tumor metastasis suppressor nm23. J Biol Chem 2002;277:38197-204.

77. Lopez-Egido J, Cunningham J, Berg M, Oberg K, Bongcam-Rudloff E, Gobl A. Menin's interaction with glial fibrillary acidic protein and vimentin suggests a role for the intermediate filament network in regulating menin activity. Exp Cell Res 2002;278:175-83.

78. Agarwal SK, Novotny EA, Crabtree JS, Weitzman JB, Yaniv $M$, Burns $A L$, et al. Transcription factor JunD, deprived of menin, switches from growth suppressor to growth promoter. Proc Natl Acad Sci USA 2003;100: 10770-5.

79. Stratakis CA, Schussheim DH, Freedman SM, Keil MF, Pack SD, Agarwal SK, et al. Pituitary macroadenoma in a 5-year-old: An early expression of multiple endocrine neoplasia type 1. J Clin Endocrinol Metab 2000:85:4776-80.
80. Brandi ML, Gagel RF, Angeli A, Bilezikian JP, Beck-Pec$\operatorname{coz} \mathrm{P}$, Bordi $\mathrm{C}$, et al. Guidelines for diagnosis and therapy of MEN type 1 and type 2. J Clin Endocrinol Metab, 2001;86:5658-71.

81. Skogseid B, Rastad J, Oberg K. Multiple endocrine neoplasia type 1. Clinical features and screening. Endocrinol Metab Clin North Am 1994;23:1-18.

82. Crabtree JS, Scacheri PC, Ward JM, Garrett-Beal L, Emmert-Buck MR, Edgemon KA, et al. A mouse model of multiple endocrine neoplasia, type 1, develops multiple endocrine tumors. Proc Natl Acad Sci USA 2001;98:1118-23.

83. Buck MR, Remaley A, Miller M, Turner E, Alexander HR, Arnold $A$, et al. Parathyroid gland-specific deletion of the mouse MEN 1 gene results in parathyroid neoplasia and hypercalcemic hyperparathyroidism. Cancer Res 2003:63:8022-28.

84. Crabtree JS, Scacheri PC, Ward JM, McNally SR, Swain GP, Montagna C, et al. Of mice and MEN 1: Insulinomas in a conditional mouse knockout. Mol Cell Biol 2003;23:6075-85.

\section{Endereço para correspondência:}

Omar M. Hauache

Disciplina de Endocrinologia - EPM/UNIFESP

Rua Pedro de Toledo $781,12^{\circ}$ andar

04039-032 São Paulo, SP

Fax: (11) 5084-5231

E-mail: ohauache-endo@pesquisa.epm.br 